\title{
Clinical, Pathological, and Molecular Factors of Aggressiveness in Lactotroph Tumours
}

\author{
Jacqueline Trouillas ${ }^{a, b}$ Etienne Delgrange ${ }^{c}$ Anne Wierinckx ${ }^{a, d}$ e Alexandre Vasiljevic ${ }^{a, b}, d, f$ \\ Emmanuel Jouanneau ${ }^{\mathrm{a}, \mathrm{d}, \mathrm{g}}$ Pia Burman ${ }^{\mathrm{h}}$ Gerald Raverot ${ }^{\mathrm{a}, \mathrm{b}} \mathrm{d}, \mathrm{i}$ \\ a Université de Lyon 1, Université de Lyon, Lyon, France; ${ }^{b}$ Faculté de Médecine Lyon-Est, Lyon, France; ${ }^{c}$ Service \\ d'Endocrinologie, CHU UCL Namur, Université catholique de Louvain, Mont-sur-Meuse, Belgium; ${ }^{\mathrm{d} C e n t r e ~ d e ~}$ \\ Recherche en Cancérologie de Lyon (CRCL), INSERM U1052, CNRS UMR5286, Université de Lyon, Lyon, France; \\ e ProfileXpert, SFR-Est, CNRS UMR-S3453, INSERM US7, Lyon, France; ${ }^{f}$ Centre de Pathologie et de Neuropathologie \\ Est, Groupement Hospitalier Est, Hospices Civils de Lyon, Bron, France; ${ }^{9}$ Service de Neurochirurgie Groupement \\ Hospitalier Est, Hospices Civils de Lyon, Bron, France; ' Department of Endocrinology, Skåne University Hospital, \\ Malmö, University of Lund, Lund, Sweden; 'Départment d'Endocrinologie, Centre de Référence pour les Maladies \\ Hypophysaires Rares (HYPO), Groupement Hospitalier EST, Hospices Civils de Lyon, Bron, France
}

\author{
Keywords \\ Prognostic factors - Lactotroph tumour · Sex · Pituitary \\ tumour · Prolactinoma $\cdot$ Aggressive tumours
}

\begin{abstract}
The behaviour of lactotroph tumours varies between benign tumours, those cured by treatment, and that of aggressive tumours, and carcinomas with metastasis. Identification of clinical, pathological and molecular factors is essential for the early identification of patients that may have such aggressive tumours. Plasma prolactin levels and tumour size and invasion, per se, are not prognostic factors. However, tumours appearing at a young age ( $<20$ years), especially in boys, and the presence of genetic predisposition have a poorer prognosis. In addition, lactotroph tumours in men differ from those in women, being larger, more often invasive, and resistant to dopamine agonists. They are also more often high-grade with a high risk of recurrence and malignancy. The expression of estrogen receptor $a$ is lower than
\end{abstract}

in women and is closely correlated to aggressiveness. Proliferation markers (Ki-67 expression: $\geq 3 \%$, mitotic count $n>2$ ) are correlated to invasion and proliferation, but, taken alone, their prognostic value is debatable. Based on a 5-tiered clinicopathological classification, and taking into account invasion and proliferation, a grade $2 \mathrm{~b}$ (aggressive) lactotroph tumour has a $20 \times$ risk of progression compared to a grade $1 \mathrm{a}$ (benign) tumour. Moreover, lactotroph tumours are the second-most frequent aggressive and malignant tumour. Other factors, such as the expression of growth factors (vascular endothelial growth factor [VEGF] and epidermal growth factor [EGF]), the genes regulating invasion, differentiation and proliferation, adhesion molecules (E-cadherin), matrix metalloproteinase 9, and chromosome abnormalities (chromosomes 11, 19, and 1), have also been correlated with aggressiveness. Currently, clinical signs, a prognostic classification, and molecular and genetic markers may all help the clinician in the early identification of aggressive lactotroph tumours and enable stratification of their management.

(c) 2019 S. Karger AG, Basel

\section{KARGER}

(C) 2019 S. Karger AG, Basel 


\section{Introduction}

Lactotroph tumours (prolactinomas or prolactin [PRL]-secreting adenomas) are the most common subtype of pituitary neuroendocrine tumours (PitNETs) [1] and represent approximately $30-45 \%$ of all secreting pituitary tumours [2]. There is a clear predominance in females over males of 10:1 [3,4]. Lactotroph tumours are generally considered to be benign. However, the behaviour of these tumours varies greatly, from microadenomas cured by dopamine agonist (DA) treatment or surgery, to aggressive and malignant tumours with metastases. Recently, it has been found that lactotroph tumours are the second-most frequent aggressive tumours and carcinoma (malignant tumours) [5]. Identification of clinical, pathological, and molecular factors is essential to identify patients harbouring aggressive lactotroph tumours, in order to be able to implement intensive therapy and careful long-term follow-up. Twelve years after the excellent review by Gürlek et al. [6], in this review, based on the literature and our personal research, we also endeavour to answer the question: "Can we identify factors of aggressiveness in lactotroph tumours?".

\section{Clinical and Biological Factors}

\section{Age, Plasma Prolactin Levels, and Tumour Size and \\ Invasion}

Young age ( $<20$ years) is associated with large and invasive lactotroph tumours. In a young patient, such a tumour should prompt exploration for a possible genetic predisposition ( $\mathrm{MEN}_{1}$ or AIP mutation), which is associated with a poorer prognosis [7].

There is a correlation between PRL level and tumour size, and a high PRL level is associated with a poor surgical outcome, although it is not an independent predictor of the response to DA therapy. On the contrary, a relatively low PRL level, with respect to tumour size, could be a sign of poor differentiation. However, it must be kept in mind that this is a rare eventuality. Usually, a large tumour with PRL plasma levels $<200 \mathrm{ng} / \mathrm{mL}$ is due to a stalk disconnection. Giant lactotroph tumours usually respond well to DA therapy $[8,9]$, with a complete normalization of PRL levels and significant tumour shrinkage. However, large tumours are more likely to be invasive. Invasion towards the cavernous sinus constitutes an independent predictor of resistance to medical treatment. However, tumour size or invasion, per se, does not predict aggressive behaviour of the tumour.

Factors of Aggressiveness in Lactotroph Tumours

\section{Lactotroph Tumours and Gender}

Since the 1980s, neurosurgeons have noticed that lactotroph tumours in men are generally larger than those in women, and are less often cured by surgery $[10,11]$. These differences have been related to the delay in diagnosis in male patients. Indeed, women of reproductive age usually present with microprolactinomas, while men and post-menopausal women typically develop macroprolactinomas [12]. A longer delay in diagnosis due to symptoms being less obvious in men may contribute to this finding, but this is unlikely the full explanation. Indeed, the difference in tumour size is already present in children at a very young age. Tumours are significantly larger and more frequently invasive in boys than in girls (70 and 38\%, respectively) [7] and all cases of giant tumours described until now in children $<15$ years were in boys [8]. We also found that men had larger tumours than women, when correlated for age at diagnosis and duration of symptoms [13]. Interestingly, lactotroph tumours in men and women show different characteristics on magnetic resonance imaging, with low signal intensity on T2-weighted images being found almost exclusively in men [14]. Taken together, these studies demonstrate a gender difference in tumour behaviour. In addition to being larger, lactotroph tumours in men more often invade the cavernous sinus, have higher Ki-67 indices, and are more often well-vascularized [13, 15-17]. The tumours in men are also more often resistant to treatment with DAs than in women [13], and display a clinically more aggressive course, such as more frequent recurrence after surgery, tumour progression under treatment (DA and radiotherapy $[13,18]$ ), and more frequently developing into carcinomas. Generally, in men, lactotroph tumours express lower levels of estrogen receptor (ER)a [18]. This finding may be explained by a lower degree of differentiation. Moreover, in some animal models, estrogens have been shown to inhibit tumour growth [19-21]. This inhibition by estrogens might explain the bimodal distribution of giant lactotroph tumours in young and old women $[8,22]$. Therefore, in both men and post-menopausal women, lower ER $\alpha$ expression, combined with low estrogen production, may enhance proliferation and give rise to highgrade (grade $2 \mathrm{~b}$ ) tumours. The clinical and biological sex-related differences have since been confirmed by molecular and genetic studies (see below) (Fig. 1). In the 2017 WHO classification [23], lactotroph tumours in men are identified as lactotroph tumours that "commonly show aggressive behaviour" which require close follow-up.

Neuroendocrinology 2019;109:70-76 DOI: $10.1159 / 000499382$ 


\section{Resistance to DAs}

DA therapy is the first-line treatment for lactotroph tumours, especially in case of extrasellar extension. The absence of complete normalization of serum PRL levels despite prolonged high-dose treatment is rare (around $10 \%)$ but these tumours exhibit a more severe clinical course than DA-sensitive ones [24, 25]. DA-resistant tumours are larger and more frequently invasive than DAresponsive tumours, and they have a higher Ki-67 index and mitotic count than other lactotroph tumours $[13,17]$. DA-resistant lactotroph tumours are frequently found in men, even when considering only macroadenomas [13, 26]. Primary or secondary DA resistance has been described in aggressive or malignant tumours [27, 28]. This may be related to a de-differentiation related to aggressiveness or malignancy. Indeed, this resistance may be due to a low expression of $\mathrm{D}_{2}$ receptor $\left(\mathrm{D}_{2} \mathrm{R}\right)$. This hypothesis is based on studies in vitro [29] and in an animal model, i.e., the $\mathrm{D}_{2} \mathrm{R}$ knockout (KO)-transgenic mouse, which develops invasive lactotroph tumours [30]. In a cohort of DA-resistant lactotroph tumours, no mutation of the $D_{2} R$ gene was reported [31]. Due to the lack of specific commercial antibodies, profiling of $\mathrm{D}_{2} \mathrm{R}$ using immunohistochemistry (IHC) is not yet possible. DA resistance therefore necessitates close patient follow-up, and more aggressive therapy such as surgery and radiotherapy.

\section{Pathological Markers}

\section{Proliferation Markers}

$\mathrm{Ki}-67$, which is expressed throughout the cell cycle, is now detected on routine histopathology, using IHC with a monoclonal antibody (Mib-1). The Ki-67 index, defined as the percentage of Ki-67-positive nuclei, is an easy, reliable, and reproducible method. Although its correlation with tumour growth and invasion may be debatable, a Ki67 index with a cut off $\geq 3 \%$ is considered to be a sign of proliferation.

The number of mitoses is also an important predictive factor of rapid growth. A pituitary tumour is considered as proliferative if the number of mitoses observed is $>2$ per 10 high-power fields. A mitotic count of $>2$ and a Ki-67 index $\geq 3 \%$ have been found to be correlated with DA-resistant and invasive lactotroph tumours, especially in men [17].

Expression of the p53 tumour suppressor gene product is reported to be an important marker in many cancers. However, p53 mutation has not been described in pituitary tumours and the value of its detection is controversial due to accompanying technical problems.
Pituitary tumour-transforming gene (PTTG), a member of the securin family that regulates sister chromatid separation during mitosis [32], has also been found to be overexpressed in invasive lactotroph tumours compared to their non-invasive counterparts [33].

\section{A Clinicopathological, Five-Tiered Classification}

We proposed a new clinicopathological, 5-tiered classification of PitNETs [34] that considers invasion (assessed by pituitary imaging), the immunohistological subtype, and proliferation markers (Ki-67 index, mitotic count, and p53 positivity). Tumours were classified according to size (micro-, macro-, and giant tumours), type (somatotroph, lactotroph, corticotroph, gonadotroph, and thyrotroph), and grade (1a: non-invasive, $1 \mathrm{~b}$ : noninvasive and proliferative, $2 \mathrm{a}$ : invasive, $2 \mathrm{~b}$ : invasive and proliferative, and 3: metastatic). The prognostic value of this classification has been statistically demonstrated by a case control study on a large retrospective cohort [34]. It has also been recently confirmed by a prospective study [35] and 2 other independent retrospective studies [36, 37]. It must be underlined that the vast majority of pituitary tumours are benign and are cured by surgery or medical treatment. In lactotroph tumours, the frequency of grade 1a (benign) and grade $2 \mathrm{~b}$ (aggressive) tumours was 56 and $16 \%$, respectively. A grade $2 b$ tumour has a $20 \times$ higher risk of recurrence or progression during follow-up than a grade 1a tumour [34]. These results confirmed our previous observations [38].

\section{Aggressive and Malignant Lactotroph Tumours}

An aggressive tumour has been defined as "an invasive tumour with rapid growth, resistant to standard treatments (medical treatment, surgery and radiotherapy), with multiple recurrence or progression" [39]. The frequency of grade $2 \mathrm{~b}$ tumours is about $10 \%$ of all types in a surgical series [35], but $2 \%$ of all tumours could be clinically considered as aggressive based on this previous definition [5]. Until now, only rare tumours with metastases are considered as malignant and termed carcinomas $(0.2 \%)$. However, the differences between aggressive tumours and carcinomas are not clear, and we suggested grade $2 \mathrm{~b}$ tumours should be considered as a "tumour suspected of malignancy" [40]. It has been recently postulated that aggressive tumours and carcinomas are 2 sides of the same coin, and that aggressive or grade $2 b$ tumours represent tumours "with malignant potential" [41]. Lactotroph tumours are the second-most frequent aggres-
Trouillas/Delgrange/Wierinckx/ Vasiljevic/Jouanneau/Burman/Raverot 
sive and malignant tumours after corticotroph tumours, with frequencies of 20 and 37\%, respectively [5]. To elucidate the mechanisms and factors of progression and malignancy, it is important to compare the tumour at first presentation and after repeat surgeries, as sometimes done [28]. A comparison of benign and aggressive tumours is also important. For these reasons, we focussed our research on this type of pituitary tumour.

\section{Molecular and Genetic Markers}

Recent progress in molecular and genetic techniques (transcriptome, comparative genetic hybridization, and epigenetics) has enabled identification of variations in gene expression (microRNA and mRNA), loss of heterozygosity, and detection of gene mutations in pituitary tumours. To date, their detection has only been performed at the research level.

\section{Estrogen Receptors}

Normal lactotroph cells as well as most lactotroph tumours generally express ERa [42]. ERa expression has been correlated with tumour size [43]. Using IHC and microarrays, we demonstrated a low level of ERa expression, especially in male patients. Clinical and pathological correlations in 81 patients demonstrated that a low expression of ER (an IHC score $<6$ ) was statistically correlated with tumour size and invasion, Ki-67 index, mitotic count, p53 expression, a high tumour grade (grade $2 \mathrm{~b}$ ), surgical cure, DA resistance, and tumour progression $[18,44]$. If this gets validated in other series, ER immunostaining could be used as a prognostic marker and be systematically tested for lactotroph tumours. Moreover, many genes differentially expressed in men and women were found to belong to the ER pathway, and 3 such genes (CTAG2, FGF13, and $V E G F)$ are located on the $\mathrm{X}$ chromosome. A number of ER-related candidate genes such as SLC6A8, a transporter inhibited by estrogens, are also overexpressed in men [44]. Thus, ER $\alpha$ expression may drive the sex differences that are observed in aggressive and malignant lactotroph tumours in men. However, other genes, such as FGF13, which is differentially upregulated in lactotroph tumours in men, could also contribute to the aggressive behaviour of lactotroph tumours in men [44].

\section{Growth Factors}

Vascular endothelial growth factor (VEGF) and its receptor (VEGFR) regulate cell growth, cell differentiation, endothelial migration, and angiogenesis [45]. Using a

Factors of Aggressiveness in Lactotroph Tumours number of methods (IHC, Western blot, and qRT-PCR), it has been shown that VEGF is overexpressed in many lactotroph tumours [46]. VEGF expression is also higher in men than in women [44] and higher in pituitary carcinoma than in benign adenoma [47]. A malignant lactotroph tumour illustrates the importance of VEGF [28]. This tumour shows neoangiogenesis with endothelial cell expression of endocan. This proteoglycan, secreted by endothelial cells and controlled by VEGF and fibroblast growth factor, has been associated with the invasion and progression of pituitary tumours [48]. This overexpression of VEGF in lactotroph tumours could therefore be of therapeutic interest. Indeed, it has also been reported that an anti-VEGF treatment (bevacizumab) stabilized progression in a case of pituitary carcinoma and induced extensive perivascular fibrosis [49]. Furthermore, it has been found that EGF-binding sites are present in $76.5 \%$ of lactotroph tumours and are more frequently expressed in invasive than non-invasive tumours [50]. This pathway could thus also represent a therapeutic target for aggressive lactotroph tumours. Indeed, lapatinib, a tyrosine-kinase inhibitor targeting EGFR and erbB2 tyrosine-kinase, was shown to inhibit PRL secretion in 2 patients resistant to high-dose cabergoline [51].

\section{Genes of Proliferation and Invasion}

The comparison of aggressive (grade $2 \mathrm{~b}$ ) and non-aggressive (grade 1a and grade 2a) lactotroph tumours demonstrated that the expression of 7 genes implicated in invasion (ADAMTS6 and CRMP1) or proliferation (PTTG, $A S K, C C N B 1, A U R K B$, and CENPE) correlated with invasion, pathological classification, persistence, and progression of the disease [38]. Moreover, there was an inverse correlation between aggressiveness and the expression level of 4 microRNAs (miRNAs): miR-183 which acts as an anti-proliferative gene by directly targeting KIAA0101, miR-340 with its target genes (NEK2, AURKB, and CCNB2), miR-744 and its target gene (TGFB1), and miR98 and its target genes (CENPK, UBE2T, and E2F2) [52]. Four genes (CENPE, AURKB, CCNB1, and ADAMTS6) were correlated with the up-regulation of CTAG2, which has previously been associated with invasion in breast cancer [53]. The differential expression of these genes and the modulation of miRNA expression involved in proliferation and invasion may play a role in tumour aggressiveness $[52,54,55]$.

\section{Adhesion Molecules and Metalloproteases}

The cadherin/ $\beta$-catenin complex is considered as "an invasion suppressor system." Its expression is lower in 


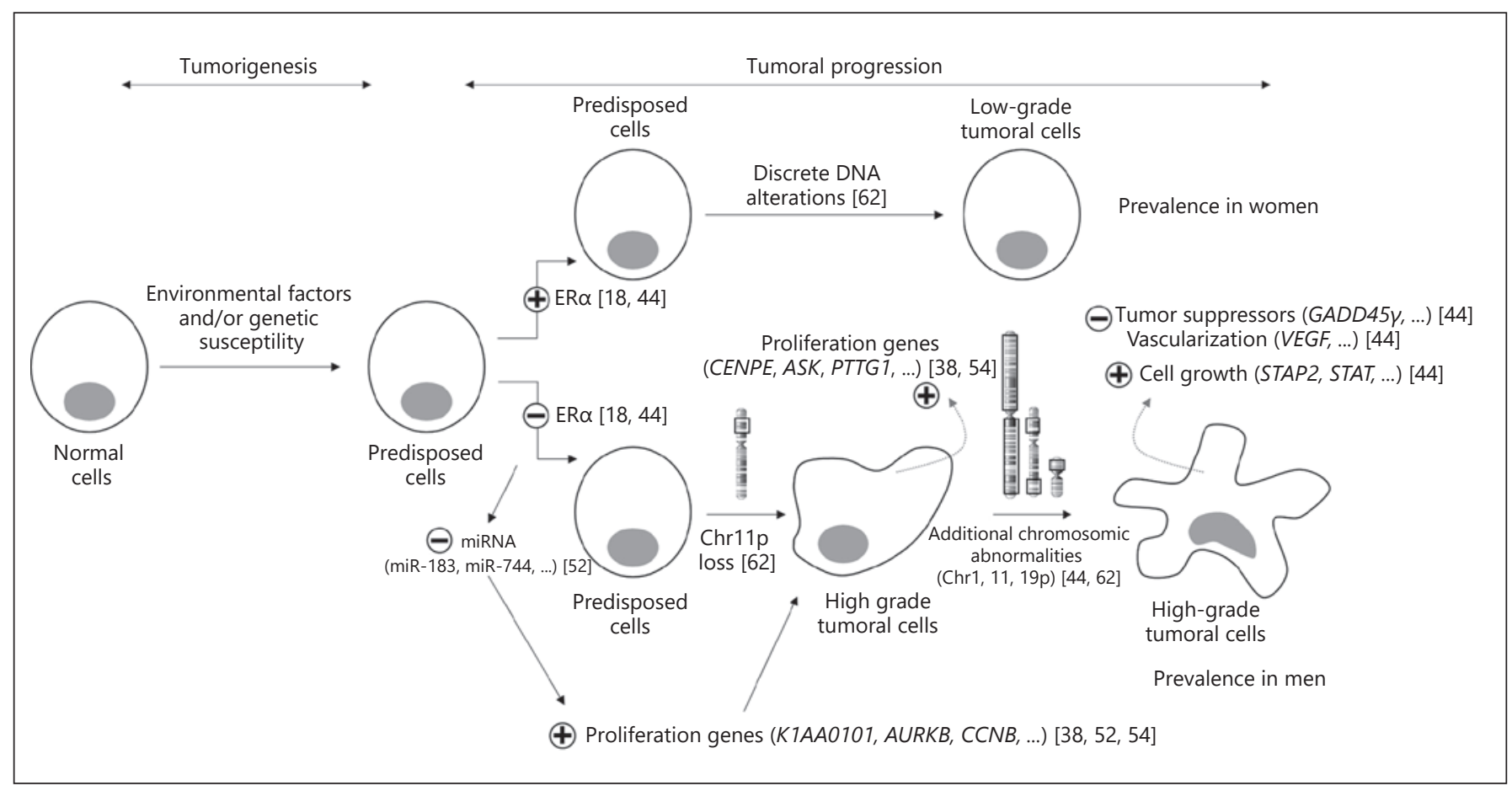

Fig. 1. Mechanisms of tumour progression, sex-related differences and main factors of aggressiveness in lactotroph tumours (modified from Wierinckx et al. [44]). The other references cited are: Delgrange et al. [18], Raverot et al. [38], Roche et al. [52], and Wierinckx et al. [54, 62].

invasive than in non-invasive lactotroph tumours, and lower in men than in women [56].

Matrix metalloproteinases (MMPs) are a family of enzymes, which can degrade the basement membranes and thus promote tumour invasion, while also contributing to endothelial cell migration. The activities of MMPs are regulated by tissue inhibitors of metalloproteinases (TIMPs) [57]. It has been demonstrated that MMP9 expression is correlated with angiogenesis. MMP9 expression was found to be higher in invasive lactotroph tumours and carcinomas than in non-invasive tumours [58, 59]. Conversely, the MMP inhibitor, TIMP-2, was overexpressed in non-invasive tumours when compared with invasive adenomas [60]. These observations suggest that MMPs may play an important role in the aggressiveness of lactotroph tumours.

\section{Chromosome Abnormalities}

A loss of heterozygosity, especially in chromosome 11 (Chr11), is found more often in invasive tumours than in non-invasive tumours [61]. Specifically, the Chr11p region is commonly deleted in aggressive lactotroph tumours (grade 2b) [62]; a loss of the whole Chr11 and a gain in the 1q arm was observed in 3 aggressive tumours that developed metastases during follow-up and were thus considered as malignant. This abnormality of Chr11, where the Menin gene is located, may be related to the frequency of lactotroph tumours in MEN1 patients. A gain of Chr19 has been observed in aggressive lactotroph tumours in men [44]. A trisomy of Chr12 with overexpression of $\mathrm{HMGA}_{2}$, which is located on this chromosome, has also been described [63].

Molecular and genetic analyses are therefore useful for identifying new markers of aggressiveness or malignancy, and to elucidate the mechanisms of tumour progression and sex-related differences (Fig. 1).

\section{Conclusion}

Lactotroph tumour types vary from small benign tumours that are cured by surgery or DA treatment in the vast majority of patients (especially women), to aggressive tumours that grow quickly, recur, and are resistant to DA treatment (more often seen in men). The identification of aggressive lactotroph tumours is of major clinical 
importance. Indeed, despite the absence of metastasis, they are "suspected of malignancy" or have "a malignant potential," and are associated with elevated morbidity and mortality. Clinical signs, a prognostic pathological classification, and molecular and genetic markers may help the clinician in the early identification of these aggressive lactotroph tumours and enable the stratification of their management. For this type of pituitary tumour, in particular, a multidisciplinary approach is key in both clinical practice and research.

\section{Acknowledgments}

This paper was revised by an independent scientific English language-editing service.

\section{References}

1 Asa SL, Casar-Borota O, Chanson P, Delgrange E, Earls P, Ezzat S, et al; Attendees of 14th Meeting of the International Pituitary Pathology Club, Annecy, France, November 2016. From pituitary adenoma to pituitary neuroendocrine tumor (PitNET): An International Pituitary Pathology Club proposal. Endocr Relat Cancer. 2017 Apr;24(4):C5-8.

2 Ciccarelli A, Daly AF, Beckers A. The epidemiology of prolactinomas. Pituitary. 2005; 8(1):3-6.

3 Ciccarelli A, Guerra E, De Rosa M, Milone F, Zarrilli S, Lombardi G, et al. PRL secreting adenomas in male patients. Pituitary. 2005;8(1): $39-42$.

4 Colao A, Sarno AD, Cappabianca P, Briganti F, Pivonello R, Somma CD, et al. Gender differences in the prevalence, clinical features and response to cabergoline in hyperprolactinemia. Eur J Endocrinol. 2003 Mar;148(3): $325-31$.

5 McCormack A, Dekkers OM, Petersenn S, Popovic V, Trouillas J, Raverot G, et al; ESE Survey Collaborators. Treatment of aggressive pituitary tumours and carcinomas: results of a European Society of Endocrinology (ESE) survey 2016. Eur J Endocrinol. 2018 Mar;178(3):265-76.

6 Gürlek A, Karavitaki N, Ansorge O, Wass JA. What are the markers of aggressiveness in prolactinomas? Changes in cell biology, extracellular matrix components, angiogenesis and genetics. Eur J Endocrinol. 2007 Feb; 156(2):143-53.

7 Salenave S, Ancelle D, Bahougne T, Raverot G, Kamenický P, Bouligand J, et al. Macroprolactinomas in children and adolescents: factors associated with the response to treatment in 77 patients. J Clin Endocrinol Metab. 2015 Mar; 100(3):1177-86.

8 Delgrange E, Raverot G, Bex M, Burman P, Decoudier B, Devuyst F, et al. Giant prolactinomas in women. Eur J Endocrinol. 2013 Nov;170(1):31-8.

9 Shimon I, Sosa E, Mendoza V, Greenman Y, Tirosh A, Espinosa E, et al. Giant prolactinomas larger than $60 \mathrm{~mm}$ in size: a cohort of massive and aggressive prolactin-secreting pituitary adenomas. Pituitary. 2016 Aug; 19(4):429-36.
10 Pont A, Shelton R, Odell WD, Wilson CB. Prolactin-secreting tumors in men: surgical cure. Ann Intern Med. 1979 Aug;91(2):211-3.

11 Serri O, Somma M, Rasio E, Beauregard H, Hardy J. Prolactin-secreting pituitary adenomas in males: transsphenoidal microsurgical treatment. Can Med Assoc J. 1980 May; 122(9):1007-13.

12 Raappana A, Koivukangas J, Ebeling T, Pirilä $\mathrm{T}$. Incidence of pituitary adenomas in Northern Finland in 1992-2007. J Clin Endocrinol Metab. 2010 Sep;95(9):4268-75.

13 Delgrange E, Trouillas J, Maiter D, Donckier J, Tourniaire J. Sex-related difference in the growth of prolactinomas: a clinical and proliferation marker study. J Clin Endocrinol Metab. 1997 Jul;82(7):2102-7.

14 Kreutz J, Vroonen L, Cattin F, Petrossians P, Thiry A, Rostomyan L, et al. Intensity of prolactinoma on T2-weighted magnetic resonance imaging: towards another gender difference. Neuroradiology. 2015 Jul;57(7):679-84.

15 Berezin M, Shimon I, Hadani M. Prolactinoma in 53 men: clinical characteristics and modes of treatment (male prolactinoma). J Endocrinol Invest. 1995 Jun;18(6):436-41.

16 Shimon I, Benbassat C, Hadani M. Effectiveness of long-term cabergoline treatment for giant prolactinoma: study of 12 men. Eur J Endocrinol. 2007 Feb;156(2):225-31.

17 Delgrange E, Sassolas G, Perrin G, Jan M, Trouillas J. Clinical and histological correlations in prolactinomas, with special reference to bromocriptine resistance. Acta Neurochir (Wien). 2005 Jul;147(7):751-7.

18 Delgrange E, Vasiljevic A, Wierinckx A, François P, Jouanneau E, Raverot G, et al. Expression of estrogen receptor alpha is associated with prolactin pituitary tumor prognosis and supports the sex-related difference in tumor growth. Eur J Endocrinol. 2015 Jun;172(6): 791-801.

19 Lloyd RV, Landefeld TD, Maslar I, Frohman LA. Diethylstilbestrol inhibits tumor growth and prolactin production in rat pituitary tumors. Am J Pathol. 1985 Mar;118(3):379-86.

20 Morel Y, Albaladejo V, Bouvier J, Andre J. Inhibition by 17 beta-estradiol of the growth of the rat pituitary transplantable tumor MtF4. Cancer Res. 1982 Apr;42(4):1492-7.
21 Trouillas J, Morel Y, Pharaboz MO, Cordier G, Girod C, Andre J. Morphofunctional modifications associated with the inhibition by estradiol of MtTF4 rat pituitary tumor growth. Cancer Res. 1984 Sep;44(9):4046-52.

22 Shimon I, Bronstein MD, Shapiro J, Tsvetov G, Benbassat C, Barkan A. Women with prolactinomas presented at the postmenopausal period. Endocrine. 2014 Dec;47(3):889-94.

23 Osamura RY, Grossman A, Korbonits M, Kovacs $K$, Lopes MB, Matsuno A, et al. Pituitary adenoma. In: Tumours of the Pituitary. 4 th ed. Lloyd RV, Osamura RY, Klöppel G, Rosai J, editors. Lyon: IARC; 2017. p. 13-18.

24 Brue T, Pellegrini I, Priou A, Morange I, Jaquet $P$. Prolactinomas and resistance to dopamine agonists. Horm Res. 1992;38(1-2):84-9.

25 Vroonen L, Jaffrain-Rea ML, Petrossians P, Tamagno G, Chanson P, Vilar L, et al. Prolactinomas resistant to standard doses of cabergoline: a multicenter study of 92 patients. Eur J Endocrinol. 2012 Nov; 167(5):651-62.

26 Delgrange E, Daems T, Verhelst J, Abs R, Maiter D. Characterization of resistance to the prolactin-lowering effects of cabergoline in macroprolactinomas: a study in 122 patients. Eur J Endocrinol. 2009 May;160(5): 747-52.

27 Sbardella E, Farah G, Fathelrahman A, Cudlip S, Ansorge O, Karavitaki N, et al. A macroprolactinoma becoming resistant to cabergoline and developing atypical pathology. Endocrinol Diabetes Metab Case Rep. 2016;2016: $1-5$.

28 Zemmoura I, Wierinckx A, Vasiljevic A, Jan M, Trouillas J, François P. Aggressive and malignant prolactin pituitary tumors: pathological diagnosis and patient management. Pituitary. 2013 Dec;16(4):515-22.

29 Caccavelli L, Feron F, Morange I, Rouer E, Benarous R, Dewailly D, et al. Decreased expression of the two D2 dopamine receptor isoforms in bromocriptine-resistant prolactinomas. Neuroendocrinology. 1994 Sep;60(3): 314-22.

30 Kelly MA, Rubinstein M, Asa SL, Zhang G, Saez C, Bunzow JR, et al. Pituitary lactotroph hyperplasia and chronic hyperprolactinemia in dopamine D2 receptor-deficient mice. Neuron. 1997 Jul;19(1):103-13. 
31 Friedman E, Adams EF, Höög A, Gejman PV, Carson E, Larsson C, et al. Normal structural dopamine type 2 receptor gene in prolactinsecreting and other pituitary tumors. J Clin Endocrinol Metab. 1994 Mar;78(3):568-74.

32 Zhang X, Horwitz GA, Prezant TR, Valentini A, Nakashima M, Bronstein MD, et al. Structure, expression, and function of human pituitary tumor-transforming gene (PTTG). Mol Endocrinol. 1999 Jan;13(1):156-66.

33 Zhang X, Horwitz GA, Heaney AP, Nakashima M, Prezant TR, Bronstein MD, et al. Pituitary tumor transforming gene (PTTG) expression in pituitary adenomas. J Clin Endocrinol Metab. 1999 Feb;84(2):761-7.

34 Trouillas J, Roy P, Sturm N, Dantony E, Cortet-Rudelli C, Viennet G, et al.; members of HYPOPRONOS. A new prognostic clinicopathological classification of pituitary adenomas: a multicentric case-control study of 410 patients with 8 years post-operative followup. Acta Neuropathol. 2013 Jul;126(1):12335.

35 Raverot G, Dantony E, Beauvy J, Vasiljevic A, Mikolasek S, Borson-Chazot F, et al. Risk of Recurrence in Pituitary Neuroendocrine Tumors: A Prospective Study Using a FiveTiered Classification. J Clin Endocrinol Metab. 2017 Sep;102(9):3368-74.

36 Lelotte J, Mourin A, Fomekong E, Michotte A, Raftopoulos C, Maiter D. Both invasiveness and proliferation criteria predict recurrence of non-functioning pituitary macroadenomas after surgery: a retrospective analysis of a monocentric cohort of 120 patients. Eur J Endocrinol. 2018 Mar;178(3):237-46.

37 Asioli S, Righi A, Iommi M, Baldovini C, Ambrosi F, Guaraldi F, et al. Validation of a Clinicopathological score for the Prediction of Post-Surgical Evolution of Pituitary Adenoma: Retrospective Analysis on 566 Patients from a Tertiary Care Centre. Eur J Endocrinol. 2019 Feb 1;180(2):127-34

38 Raverot G, Wierinckx A, Dantony E, Auger C, Chapas G, Villeneuve L, et al; HYPOPRONOS. Prognostic factors in prolactin pituitary tumors: clinical, histological, and molecular data from a series of 94 patients with a long postoperative follow-up. J Clin Endocrinol Metab. 2010 Apr;95(4):1708-16.

39 Raverot G, Burman P, McCormack A, Heaney A, Petersenn S, Popovic V, et al.; European Society of Endocrinology. European Society of Endocrinology Clinical Practice Guidelines for the management of aggressive pituitary tumours and carcinomas. Eur J Endocrinol. 2018 Jan;178(1):G1-24.

40 Trouillas J. In search of a prognostic classification of endocrine pituitary tumors. Endocr Pathol. 2014 Jun;25(2):124-32.
41 Trouillas J, Burman P, McCormack A, Peter senn S, Popovic V, Dekkers O, et al. Aggressive pituitary tumours and carcinomas: two sides of the same coin? Eur J Endocrinol. 2018 Jun;178(6):C7-9.

42 Stefaneanu L, Kovacs K, Horvath E, Lloyd RV, Buchfelder M, Fahlbusch R, et al. In situ hybridization study of estrogen receptor messenger ribonucleic acid in human adenohypophysial cells and pituitary adenomas. J Clin Endocrinol Metab. 1994 Jan;78(1):83-8.

$43 \mathrm{Lv} \mathrm{H}, \mathrm{Li}$ C, Gui S, Zhang Y. Expression of estrogen receptor $a$ and growth factors in human prolactinoma and its correlation with clinical features and gender. J Endocrinol Invest. $2012 \mathrm{Feb} ; 35(2): 174-80$.

44 Wierinckx A, Delgrange E, Bertolino P, François $\mathrm{P}$, Chanson P, Jouanneau E, et al. SexRelated Differences in Lactotroph Tumor Aggressiveness Are Associated with a Specific Gene-Expression Signature and Genome Instability. Front Endocrinol (Lausanne). 2018 Nov;9:706.

45 Kimura I, Honda R, Okai H, Okabe M. Vascular endothelial growth factor promotes cellcycle transition from G0 to G1 phase in subcultured endothelial cells of diabetic rat thoracic aorta. Jpn J Pharmacol. 2000 May;83(1): 47-55.

46 Wang Y, Li J, Tohti M, Hu Y, Wang S, Li W, et al. The expression profile of Dopamine D2 receptor, MGMT and VEGF in different histological subtypes of pituitary adenomas: a study of 197 cases and indications for the medical therapy. J Exp Clin Cancer Res. 2014 Jul;33(1):56.

47 Lloyd RV, Scheithauer BW, Kuroki T, Vidal S, Kovacs K, Stefaneanu L. Vascular Endothelial Growth Factor (VEGF) Expression in Human Pituitary Adenomas and Carcinomas. Endocr Pathol. 1999;10(3):229-35.

48 Cornelius A, Cortet-Rudelli C, Assaker R, Kerdraon O, Gevaert MH, Prévot V, et al. Endothelial expression of endocan is strongly associated with tumor progression in pituitary adenoma. Brain Pathol. 2012 Nov;22(6):757-64.

49 Ortiz LD, Syro LV, Scheithauer BW, Ersen A, Uribe H, Fadul CE, et al. Anti-VEGF therapy in pituitary carcinoma. Pituitary. 2012 Sep; 15(3):445-9.

50 Jaffrain-Rea ML, Petrangeli E, Lubrano C, Minniti G, Di Stefano D, Sciarra F, et al. Epidermal growth factor binding sites in human pituitary macroadenomas. J Endocrinol. 1998 Sep;158(3):425-33.

51 Cooper O, Mamelak A, Bannykh S, Carmichael J, Bonert V, Lim S, et al. Prolactinoma ErbB receptor expression and targeted therapy for aggressive tumors. Endocrine. 2014 Jun;46(2):318-27.
52 Roche M, Wierinckx A, Croze S, Rey C, Legras-Lachuer C, Morel AP, et al. Deregulation of miR-183 and KIAA0101 in Aggressive and Malignant Pituitary Tumors. Front Med (Lausanne). 2015 Aug;2:54.

53 Maine EA, Westcott JM, Prechtl AM, Dang TT, Whitehurst AW, Pearson GW. The cancer-testis antigens SPANX-A/C/D and CTAG2 promote breast cancer invasion. Oncotarget. 2016 Mar;7(12):14708-26.

54 Wierinckx A, Auger C, Devauchelle P, Reynaud A, Chevallier P, Jan M, et al. A diagnostic marker set for invasion, proliferation, and aggressiveness of prolactin pituitary tumors. Endocr Relat Cancer. 2007 Sep;14(3):887-900.

55 Wierinckx A, Raverot G, Nazaret N, Jouanneau E, Auger C, Lachuer J, et al. Proliferation markers of human pituitary tumors: contribution of a genome-wide transcriptome approach. $\mathrm{Mol}$ Cell Endocrinol. 2010 Sep;326(1-2):30-9.

56 Qian ZR, Li CC, Yamasaki H, Mizusawa N, Yoshimoto K, Yamada S, et al. Role of E-cadherin, alpha-, beta-, and gamma-catenins, and p120 (cell adhesion molecules) in prolactinoma behavior. Mod Pathol. 2002 Dec: 15(12):1357-65.

57 Murphy G, Docherty AJ. The matrix metalloproteinases and their inhibitors. Am J Respir Cell Mol Biol. 1992 Aug;7(2):120-5.

58 Kawamoto H, Kawamoto K, Mizoue T, Uozumi T, Arita K, Kurisu K. Matrix metalloproteinase- 9 secretion by human pituitary adenomas detected by cell immunoblot analysis. Acta Neurochir (Wien). 1996;138(12):1442-8.

59 Turner HE, Nagy Z, Esiri MM, Harris AL, Wass JA. Role of matrix metalloproteinase 9 in pituitary tumor behavior. J Clin Endocrinol Metab. 2000 Aug;85(8):2931-5.

60 Knappe UJ, Hagel C, Lisboa BW, Wilczak W, Lüdecke DK, Saeger W. Expression of serine proteases and metalloproteinases in human pituitary adenomas and anterior pituitary lobe tissue. Acta Neuropathol. 2003 Nov; 106(5):471-8.

61 Bates AS, Farrell WE, Bicknell EJ, McNicol AM, Talbot AJ, Broome JC, et al. Allelic deletion in pituitary adenomas reflects aggressive biological activity and has potential value as a prognostic marker. J Clin Endocrinol Metab. 1997 Mar;82(3):818-24.

62 Wierinckx A, Roche M, Raverot G, LegrasLachuer C, Croze S, Nazaret N, et al. Integrated genomic profiling identifies loss of chromosome 11p impacting transcriptomic activity in aggressive pituitary PRL tumors. Brain Pathol. 2011 Sep;21(5):533-43.

63 Finelli P, Pierantoni GM, Giardino D, Losa M, Rodeschini O, Fedele M, et al. The High Mobility Group A2 gene is amplified and overexpressed in human prolactinomas. Cancer Res. 2002 Apr;62(8):2398-405. 